\title{
Urgences
}

\section{Un cheval pour royaume}

\section{Noël Audet}

Numéro 11, 3e trimestre 1984

URI : https://id.erudit.org/iderudit/025169ar

DOI : https://doi.org/10.7202/025169ar

Aller au sommaire du numéro

Éditeur(s)

Urgences

ISSN

0226-9554 (imprimé)

1927-3924 (numérique)

Découvrir la revue

Citer ce document

Audet, N. (1984). Un cheval pour royaume. Urgences, (11), 15-20.

https://doi.org/10.7202/025169ar

Ce document est protégé par la loi sur le droit d'auteur. L'utilisation des services d'Érudit (y compris la reproduction) est assujettie à sa politique d'utilisation que vous pouvez consulter en ligne.

https://apropos.erudit.org/fr/usagers/politique-dutilisation/
Cet article est diffusé et préservé par Érudit.

Érudit est un consortium interuniversitaire sans but lucratif composé de l’Université de Montréal, l'Université Laval et l'Université du Québec à Montréal. Il a pour mission la promotion et la valorisation de la recherche. https://www.erudit.org/fr/ 
NOËL AUDET

\section{Un cheval pour royaume}




\section{UN CHEVAL POUR ROYAUME}

Ils disaient tous à mon père:

- Nicolas! c'est le temps de la tuer, ta picouille!

Un cheval qui n'avait pas cinq ans! Et mon père se contentait de hocher la tête, en silence. II attendait quelque chose, comme un miracle qui surviendrait et lui sauverait sa bête. Depuis dix jours, King ne mangeait plus, ne buvait plus, et malgré tous ses efforts, mon père n'arrivait plus à lui faire desserrer les mâchoires.

Le miracle survint un dimanche soir: c'était mon frère aîné qui arrivait des chantiers et allait prendre l'affaire en main. Car Frédéric en avait vu d'autres là-bas, dans le Nord, il ne se laisserait pas longtemps impressionner par un petit problème domestique. II tenait des vieux une recette infaillible. À peine remis de son voyage, il se rendit à l'étable, suivi de toute la famille, à l'exception de ma mère.

- Il faut simplement le tuer, disait-elle, pour l'empêcher de souffrir.

Comme je n'avais pas dix ans, je ne comprenais pas ce raisonnement, et le remède me semblait bien douteux par rapport au mal.

- Le tuer pour le guérir de la souffrance?

- Non, pour qu'il ne souffre plus.

Mais dans ma tête d'enfant, je croyais que la mort n'était que le comble de la souffrance, une souffrance si atroce que la vie préférait fuir, se sauver de tout bord tout côté, comme on abandonne un navire en flamme. Comme le cochon qu'on saigne sous I'horrible plainte. Je ne connaissais pas de mort douce. Elle logeait toujours à l'extrême pointe de la violence. 
II faut dire qu'entre King et moi, il s'en était passé des choses. Nous avions nos petits secrets, nos dialogues muets, nos connivences. Quand il était au pacage, le dimanche aprèsmidi, je me rendais dans les champs pour lui tenir compagnie. Il feignait d'abord de ne pas me voir, puis il s'approchait tranquillement, comme si l'herbe était meilleure de mon côté. Je lui caressais I'encolure et je montais d'un coup sur son dos. C'était le signal. II relevait la tête et partait vers le bout de la terre, au petit trot. Je me sentais comme un seigneur en son domaine, rien ne pouvait nous arrêter, nous séparer. Nous étions enveloppés dans la même chaleur, nous respirions du même souffle, et quand il s'ébrouait, j'éclatais de rire. Pour me rafraîchir, je jetais de temps à autre un regard vers la mer. Je sentais bien que ce cheval-là aurait traversé l'océan. Je l'imaginais facilement bateau, et nous n'avions plus de frontières. King le corsaire, King la goélette, King le goéland. En avant, toutes!

La maladie de King s'abattit sur moi comme un ouragan, ou plutôt comme le silence après la tempête. Son oeil devint morne et triste, il essayait de me faire comprendre que le temps n'était plus au jeu, il arrivait mal à cacher son boitillement de la patte avant droite. Nos rêves de conquête retombaient en miettes fines comme des aiguilles.

- Lève la patte! dit Frédéric en lui donnant une petite tape derrière le genou.

Mais King était immobile comme une statue, les quatre membres raidis, la tête toujours haute cependant. Frédéric put enfin lever le sabot, examiner la plaie: un simple petit trou, d'où I'on avait retiré un long clou rouillé.

\section{- Ça devrait aller, dit-il.}

On le brossa avant de lui passer le licou, puis Frédéric s'empara d'une masse et il l'entraîna vers le haut de la terre. King connaissait trop bien le chemin pour l'avoir parcouru avec moi dans ses heures de gloire, mais ce jour-là, il avait l'air un peu ridicule, comme s'il marchait sur des échasses. 
- Pourquoi la masse? demandai-je à Frédéric.

- C'est le remède, dit-il, l'oeil piqué de malice.

- Pourquoi les pelles? fis-je à l'intention de mon père.

- Pour ne pas être obligé de redescendre.

Je savais tout, sans qu'ils aient eu besoin d'expliquer. Et tout le long du chemin, je lui ai caressé le flanc pour qu'il sente un peu de tendresse.

- Un si bon cheval.

- Tout juste bien dompté. Qui commençait à rapporter.

Arrivés en haut du champ, on fit cercle autour de lui, en silence. Frédéric dit soudain:

- Tout est dans la manière. Si je réussis, il ouvre la gueule, il est sauvé. Si je rate...

J'ai compris que c'était un remède de désespoir. Au premier coup de masse, en plein milieu du front, King secoua violemment la tête et tomba sur les genoux. II avait toujours les mâchoires barrées. Au deuxième coup, la masse s'enfonça avec un petit bruit mou et King s'effondra sur le côté.

Ils se sont penchés sur lui, comme des ombres, pour vérifier la mâchoire: les dents s'étaient desserrées, la gueule s'ouvrait librement. Mais King était mort.

- C'est toujours à ce moment-là qu'on les perd, dit Frédéric, juste au moment de réussir!

- C'est un drôle de remède! dit mon père, qui le tenait de la bouche même du voisin mais qui n'y croyait pas pour deux sous. II n'aurait jamais voulu assommer son cheval pour 
le guérir. II me l'a bien tué! ajouta-t-il en regardant Frédéric droit dans les yeux.

- II était déjà mort!

- On aurait pu essayer...

- Commencez pas à chialer, le père, parce que moi... j'vas faire un malheur. Le ton montait, et Frédéric jouait avec la masse.

- T'as pas appris grand-chose, dans les chantiers, si tu veux savoir...

- Pis vous, vous êtes bon pour laisser traîner partout des vieux clous rouillés, pas même capable de redresser une clôture sans traîner ses clous!

C'était peut-être lors d'une de nos promenades au bord de la route... King aurait pu marcher sur un clou... mais je ne pouvais pas le dire, même pour sauver mon père.

Après l'enterrement, nous sommes retournés à la maison, sans dire un mot. Et j'ai raconté toute la scène à ma mère, en lui parlant tout bas à l'oreille, pour que les autres n'entendent pas. J'ignore ce qu'elle a pu comprendre, car elle a dit:

- Tu sais, c'est seulement un animal. Le plus triste, c'est qu'il soit parti avant de réussir.

Réussir quoi? Je n'ai pas compris. Quelques années plus tard, ma mère était rongée par un cancer, et je regardais souvent sa bouche, comme si elle allait parler, comme si elle devait enfin tout me dire de cette étrange scène. Où l'on apparaît disparaît dans le même bond, où I'on s'abat du même mouvement, avant de saisir... Elle se contentait de sourire en me caressant la tête, pour une sorte d'encouragement je suppose. Vas-y! Fonce! semblait-elle dire. Ne pense pas aux clous le long de la route! À moins qu'elle ait voulu dire: C'est au moment où le temps allait nous faire grâce qu'il nous rattrape, 
c'est lorsque la main allait cueillir le fruit qu'elle se blesse... Je ne saurai jamais. Elle est morte les lèvres fermées, mais ses yeux continuaient de sourire. 